\title{
Pipeline Potential Leak Detection Technologies: Assessment and Perspective in the Nigeria Niger Delta Region
}

\author{
Jasper Agbakwuru \\ Offshore Technology, Faculty of Science and Technology , University of Stavanger, Norway \\ Email: jasper.agbakwuru@uis.no
}

Received August $9^{\text {th }}$, 2011; revised September 11 ${ }^{\text {th }}$, 2011; accepted October $7^{\text {th }}, 2011$.

\begin{abstract}
This paper examines the advances in pipeline third party encroachment alert systems and leak control methods in the oil/gas industry. It also highlights the extent of spill/pollution issues in the Niger Delta region due to intended/unintended damages and suggests a possible method of control. It is believed that the best option to avoid pollution due to pipeline failure is to ensure that hydrocarbon does not exit from the pipeline. With the different methods considered in this review, acoustic monitoring of change in the operational sound generated from a given pipeline section is suggested to be practicable to identifying sound abnormalities of third party encroachments. One established challenge of the acoustic system for buried pipelines protection is attenuation of acoustic transmission. An attempt to check the performance of an acoustic transmission on steel pipelines submerged in water points to a similar research on plastic water pipelines that attenuation is small compared with pipe buried in soil. Fortunately, Niger Delta of Nigeria is made of wetland, swamps and shallow water and could therefore offer an opportunity to deploy acoustic system for the safety of pipelines against third party attacks in this region. However, the numerous configuration and quantity of oil installation in this region imply that cost of application will be enormous. It is therefore suggested that a combination of impressed alternating cycle current (IACC) which traces encroachment on the pipeline coating and an acoustic system be used to manage intended and unintended pipeline potential damages. The IACC should be used for flow lines and other short distance delivery lines within the oilfield, while the relatively large diameter and long length delivery, trunk and transmission lines should be considered for acoustic protection. It is, however, noted that further efforts are required to reduce cost and improve effectiveness of these systems.
\end{abstract}

Keywords: Pipeline, Leaks, Detection, Niger Delta, Oil Spill, Oil Pollution

\section{Introduction}

Due to environmental, economic and social cost of hydrocarbon leaks, the oil and gas industry places great importance to the need to minimise ugly events of oil spill or pollution from occurring. The causes of pipeline leaks could be categorised into four main classes: Operational, structural, unintended or intended damages [1]. Operational class includes all leaks from operation of oil and gas pipelines such as equipment failure (for instance flange sealing problems due to damaged seals or loose bolts/nuts), human error etc. Structural problems include the failure of pipeline in burst, collapse, fatigue, fracture, buckling, corrosion (wall thickness loss), and internal loadings etc. The intended damages come in the form of terrorist attack, sabotage/theft. The unintended damages are those that are often caused by construction workers working in the vicinity of the pipeline.

While it is fair to put that as at today, the industry have made some significant efforts in building barriers against the activation of first two classes, there are still challenges in the latter two, especially, related to cost and effectiveness.

In describing the problem, Yo-Essien of Nigeria oil spill detection and response agency (NOSDRA) believes that the enormous oil installations deployed in the Niger Delta region explains their vulnerability to vandalism. Presently, the Niger Delta region plays host to 600 oil fields of which 360 fields are onshore while 240 are offshore with over 3000 kilometers of pipelines crisscrossing the region and linking some 275 flow stations to various export terminals. The main area of the delta is 
about $46,200 \mathrm{~km}^{2}$ (equivalent to about $1 / 20^{\text {th }}$ of the area of the country). According to him, it is pertinent to note that oil spills resulting from pipeline vandalism has continued to be a challenge, with most incidents along major pipelines and manifolds [2].

Considering the situation in the Niger Delta of Nigeria, it is imperative that the different methods and available technologies be studied in order to suggest a strategy for research and development in handling the challenges in the protection of oil and gas pipelines against growing intended and unintended damages.

This paper is motivated by the importance to have full control of the pipeline against intended and unintended damages. Recently, the Directorate of Petroleum Resources (DPR, Nigeria) claims that activities of oil theft cost Nigeria about 300,000 barrels per day. It is also reported that Nigeria lost about $\$ 1.5$ billion yearly to the crude oil theft [3]. Of recent, the Chairman of SHELL Nigeria, claims that the criminal gangs continue to steal oil from SHELL pipelines at estimated rate of 100,000 barrels per day [3] The Managing Director of SHELL in his response on the recent publication on oil spill in the region by the Amnesty International, firms that without addressing the complex issues in the Niger Delta, and without all stakeholders playing their part, this problem will continue to be on the increase [4]. This is evident in the statistical oil spill data shown in Figures 1(a) and (b) for 2011.

The recent oil spill data from SHELL Nigeria, the largest oil producing company in Nigeria, indicate that the majority of the spills have been caused by sabotage or theft. The recent spill statistical data is shown in Figures 1(a) and (b).

The several thousands of human lives lost, millions of barrels of oil spilled to the fragile environment, thousands of people displaced from their homes and millions of dollars (US) of property destroyed in the region by pipeline failures have been documented in the literature [5-7].

Construction/digging activities with improper supervision and survey in brown fields lead to unintended damages. Most often, due to fear of consequent liabilities, the pipeline operator is often not informed of such damages by the intruding construction contractors or persons, except perhaps when such damages result to obvious immediate spill/pollution. Unfortunately, most of these unintended damages in the form of external coating damages, kinks, gouges and dents deteriorate with devastating consequent failure months or years later causing safety, environmental and public concern.

This is also a global issue. Chastain (2009) quoted the API recent report of pipeline failure incident in United States between 1999 and 2006: 77\% fatalities, 49\% inci-

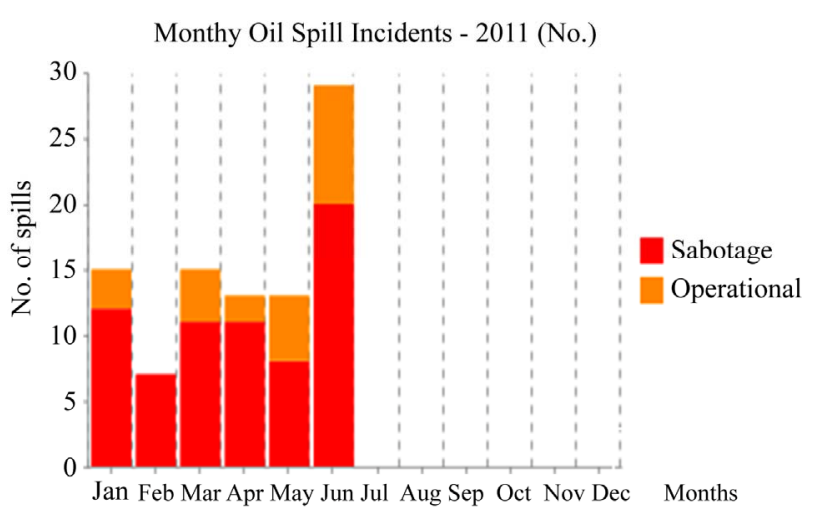

(a)

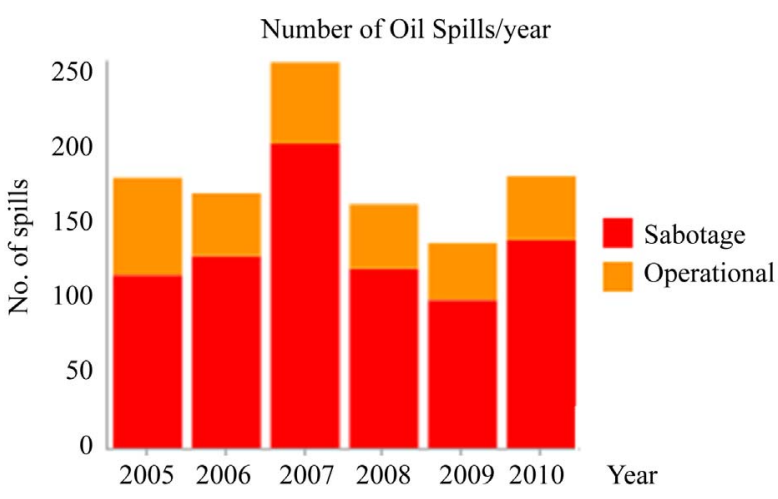

(b)

Figure 1. (a): Showing the 2011 Oil spill monthly statistics from pipelines of Shell Nigeria; (b): Showing some yearly oil spill statistics from pipelines of Shell Nigeria. (Source: SHELL Oil Spill 2011 data.

http://www.shell.com.ng/home/content/nga/environment_so ciety/respecting_the_environment/oil_spills/).

dent involving evacuations, $41 \%$ of barrels released by right of way incidents, $27 \%$ of incidents involving a release of 50 barrels or more [8].

Clearly, the prevention of damage to the pipeline must be an industry priority. Unfortunately, pipeline operators appear to have inadequate cost effective industrial technology to manage most of the pipeline exposures that generates pollution, spill or loss of hydrocarbon oil from containments such as pipelines in the class of intended and unintended actions. It is noted that till date, there has never been an effective solution for securing pipelines against damage caused by terror, sabotage, theft $[9,10]$.

A lot of patents and methodologies have been developed for the purpose of leak identification using acoustic signatures [11]. These efforts in our opinion is reactive in nature and a proactive action is required in preventing exit of oil content of oil pipelines uncontrollably to the environment with its attendant environmental, economic and social consequences. 
In this paper, various methods of hydrocarbon spill/ leak control and barriers used by the industry today have been considered. Most of the review of the technologies in this work is on an industrial context. Therefore it will be discussed with reference to the work of pipeline integrity maintenance and inspection companies most of whom are members of the Offshore Technology community [12]. This group has been selected as they are among the known major operators of innovative and modern systems for pipeline integrity systems, leaks and maintenance.

\section{Review of Leak Detection Methods}

The methods and techniques for the detection of hydrocarbon leaks from pipelines as used by the oil and gas industry to-date is reviewed and can be categorised into nine main classes based on the principle of operation (see Table 1). Details of these methods have been detailed in a review of the Pipeline Leaks and Inspection Technologies in the Oil and Gas Industry [13]. It is noted that most of the system above could be integrated to the Supervisory Control and Data Acquisition (SCADA) for alert systems in line with API RP1167.

There has been a recent development in the observations of leaking pipelines in muddy water. This development became necessary due to the underwater poor visibility inherent in the Niger Delta region, especially in the wet season [14]. Further work is in progress to enable the system to operate remotely to locate leaks.

The methods tabled in Table $\mathbf{1}$ have been identified to be useful in two areas:

1) Identifications of available leaks irrespective of the class of the causal damage

2) Potential leaks identification due to metal loss (corrosion, gouges etc.).

\section{Review of Potential Leak Detection Methods}

These are controls that are in place to stop or prevent events that would otherwise lead to escape of oil from the pipeline.

\subsection{Acoustic Systems}

The acoustic impact detection system often comprise of multiple acoustic sensors, power supply and remote transmitting devices which are placed along the pipeline at fixed intervals.

Pipeguard technology developed by Magal Security Ltd (Israel) is perhaps one of the recent technologies in this field. The company has been granted a research and development grant in March-2011 to further enhance its PipeGuard technology for protection of gas pipelines. Multiple Pipeguard sensors are typically interconnected
Table 1. Categorisation of leak detection methods.

\begin{tabular}{|c|c|c|}
\hline \multirow[b]{2}{*}{ SN } & \multicolumn{2}{|c|}{ Leak detection methods } \\
\hline & Method & $\begin{array}{l}\text { Examples of tool/systems that use the } \\
\text { method }\end{array}$ \\
\hline 1 & Laser Scanning & Laser scanning, Buckle detectors, etc. \\
\hline 2 & Ultrasonic & $\begin{array}{l}\text { Intelligent pigging, Automatic } \\
\text { ultrasonic tester, TOFD, Ultrasonic } \\
\text { probe testers etc. }\end{array}$ \\
\hline 3 & Acoustic & $\begin{array}{l}\text { Acoustic Leak detector, hydrophones, } \\
\text { Electromagnetic Acoustic Transducers } \\
\text { (EMAT), piezoelectric meter etc. }\end{array}$ \\
\hline 4 & Fibre Optics & $\begin{array}{l}\text { Optical sensors (for leak, strain, fatigue } \\
\text { and ground movement detection), etc }\end{array}$ \\
\hline 5 & Visual Inspection & $\begin{array}{l}\text { Use of human eye, Inspection light, } \\
\text { Robotic crawlers etc. }\end{array}$ \\
\hline 6 & $\begin{array}{l}\text { Magnetic flux } \\
\text { leakage method }\end{array}$ & $\begin{array}{l}\text { Intelligent pigging, Eddy current, } \\
\text { Magnetic particle inspection etc. }\end{array}$ \\
\hline 7 & $\begin{array}{l}\text { Inventory accounting } \\
\text { (pressure differentials, } \\
\text { mass flow-rates etc) }\end{array}$ & Negative pressure wave detectors \\
\hline 8 & $\begin{array}{l}\text { Flourometry/ } \\
\text { Hydrocarbon Leak } \\
\text { detection sensors }\end{array}$ & $\begin{array}{l}\text { Fluorescence detectors, Hydrochemical } \\
\text { detectors. }\end{array}$ \\
\hline 9 & $\begin{array}{l}\text { Temperature based } \\
\text { sensors }\end{array}$ & Thermal spray technology etc. \\
\hline
\end{tabular}

by wireless or cellular mesh network and alarms are displayed on geospatial map before the damage is done. Reception of raw seismic signalling is achieved using several geophones in a row, highly sensitive to the frequency domain, typical to the act of digging. The location of the identified threat is derived from accurate measurement of the signal at each sensor both in term of direction and distance from the unit [9]. The company has extended this to the use of infrasonic seismic sensors with the ability of identifying threats based on their acoustic signatures. The sensors are installed few feet above the pipeline structure [8].

General Electric (GE) developed a related system popularly called ThreatScan. The ThreatScan is used for both buried and above ground pipelines. The power supply is solar with a battery back-up for "no sun" conditions. Each sensor communicates directly with the satellite system and relays data to the GE's monitoring facility where it is analysed $[8,15]$. It can be used for Sabotage warning and detection of illegal hot tapping (product theft) but in our opinion, the characteristic alert notification up to $0-30$ mins is adequate to pipeline intrusion to happen uncontrolled, jeopardising the essence of the system. This tool is currently in use by some pipeline operators in the USA.

\subsection{Patrols and Satellite}

Pipeline patrol and Security guards is the act of patrolling the pipeline right-of- way (ROW), keeping watch 
over the pipeline by air, land or sea. Use of remotely piloted aerial patrol drones can provide video or photographic features for pipeline right of way monitoring. The use of satellite is also being considered in some quarters. For pipelines in creeks, swamps and difficult terrain and where the pipelines run into thousands of kilometre, in a spaghetti network in mangrove trees and creeks as in the Nigeria Niger Delta region, this method becomes almost impossible.

\subsection{Fibre Optics Systems}

A project was initiated by the US department of Energy, Office of Fossil Energy in this area in 2001 and the overall objective was to develop and demonstrate an optical fiber intrusion detection device that would prevent outside force damage by detecting and alarming when construction equipment is near the pipeline vicinity [16]. The principle used in this project was that when heavy equipment comes into the right of way, it compresses the soil and creates vibration which changes the dynamics of the light and reflects the changes to the source. Field testing of the basic concept has been proved. However, according to the report of the project close-out, the sensitivity of the technique needs substantial improvement to be practiced in the industry [8]. This project was champion by Gas Technology Institute (GTI).

A similar product developed by Future Fibre Technology (FFT) differs by sending continuous signal instead of pulse light. Their system has also three sensing fibre strands instead of one strand used in the GTI project. Two fibre strands measure the changes in the motion, sound or vibration while the third delivers information to determine location of the event. This tool is currently being used in Europe and USA [8]. Both systems however require the fibre to be installed along and close vicinity to the pipeline

\subsection{The Impressed Alternating Cycle Current (IACC)}

This is a kind of pipeline monitoring method consisting of impressing electrical signals on the pipe by generating a time-varying voltage between the pipe and the soil at periodic locations where pipeline access is available. The signal voltage between the pipe and ground is monitored continuously at receiving stations located some distance away. Third party contact to the pipe that breaks through the coating changes the signal received at the receiving stations. Based on information recently found in published studies, it is believed that the operation of IACC on a pipeline will cause no interference with CP systems [17]. Initial results on operating pipelines showed that IACC signals could be successfully propagated over a distance of 3.5 miles $(5.63 \mathrm{~km})$, and that simulated contact can be detected up to a distance of 1.4 miles (2.4 $\mathrm{km})$, depending on the pipeline and soil conditions [17]. This method will allow existing pipelines to be retrofitted for monitoring without excavation because the technique uses existing cathodic protection (CP) test points. In addition, the method could be readily applied to new pipelines.

Huebler, (2002) gave the benefits and drawbacks of the technologies especially for pipeline right of way intrusion detection [10], many of which are presented in Table 2.

\section{Discussion}

The application of the acoustic methods in the manner of the most recent technology may require modifications for use in submerged steel pipelines and manifolds where attack or encroachment on a pipeline is not through the act of "digging or ground breaking". Verification of performance of the acoustic method in submerged pipeline is yet to be documented. An experience to trace acoustic transmission on water pipeline at depth of $12 \mathrm{~m}$ suggest that it would not pose a bigger challenge and may even prove to be easier than land based pipelines. This experience conforms to the work of Muggleton and Brennan (2004) on the sound attenuation in plastic pipelines submerged in water. They found that energy does not, in fact, radiate into the water and the attenuation is small compared with that for a pipe buried in soil [18].

In managing the noise level in acoustic methods, it could be possible to study sound generated from a given pipeline and identify the anomalies that could occur in the form of act of digging, cutting, hot tapping and drilling. And then concentrate on monitoring deviation from "normal" noise levels as a measure of control. This suggestion is relevant because most of the trunk and transmission pipelines on land are located alongside motorable roads from where most noise could be generated. (Using fibre optics in this scenario would lead to a lot of noise generation). The oil field stations in the region are not too distant from each other. The implication is that the acoustic and alternating current attenuation may be managed by localising the monitoring system to closest station as possible and identifying the "normal" conditions.

Pipeline networks in most oilfields in the Niger Delta of Nigeria are more or less "spaghetti" in swamps and shallow water. Unfortunately, the networks of pipelines are often the small flow lines in the range of 4 inch to 8inch running from various points and sometimes crossing each other. Use of acoustics and fibre optics methods for these small diameter pipelines for detection of intended and unintended damages would be technically and financially cumbersome. New method or combinations of methods would therefore be required. 
Table 2. Benefits and drawbacks of the technologies.

\begin{tabular}{|c|c|c|c|}
\hline \multirow{2}{*}{$\mathrm{SN}$} & \multicolumn{3}{|c|}{ Comparison of different technologies } \\
\hline & Technology & Benefits & Drawback \\
\hline 1 & Satellite monitoring at visible wavelengths. & $\begin{array}{l}\text { No equipment to install on ground. Uses } \\
\text { commercial satellites. Possible replacement } \\
\text { for weekly flyovers of pipelines. }\end{array}$ & $\begin{array}{l}\text { Requires sunlight. Affected by cloud cover. A } \\
\text { method is needed to pick out activity over narrow } \\
\text { pipeline in broad image }\end{array}$ \\
\hline 2 & Satellite monitoring at several wavelengths. & $\begin{array}{l}\text { Could detect encroachment at night and } \\
\text { through cloud cover. }\end{array}$ & $\begin{array}{l}\text { Requires more than one satellite. A method is } \\
\text { needed to pick out activity over narrow pipeline in } \\
\text { broad image. }\end{array}$ \\
\hline 3 & Ground-based visual surveillance. & Can use commercially available cameras. & $\begin{array}{l}\text { System is needed to minimize the amount of } \\
\text { human monitoring. May not see directional boring } \\
\text { encroachment. Separate camera needed for each } \\
\text { line-of-sight. }\end{array}$ \\
\hline 4 & $\begin{array}{l}\text { GPS system and computerized pipeline } \\
\text { maps. }\end{array}$ & No equipment installed on pipeline. & $\begin{array}{l}\text { Requires equipment on each piece of construction } \\
\text { equipment. Requires equipment operators to } \\
\text { maintain equipment. Restricted use in right of way } \\
\text { monitoring. }\end{array}$ \\
\hline 5 & $\begin{array}{l}\text { The impressed alternating cycle current } \\
\text { (IACC). }\end{array}$ & $\begin{array}{l}\text { Continuous monitoring. Could be used in } \\
\text { conjunction with acoustic detection. }\end{array}$ & $\begin{array}{l}\text { Detects rather than prevents damage. Requires } \\
\text { breaking of coating for detection. Requires } \\
\text { minimum breaks in pipeline coating. }\end{array}$ \\
\hline 6 & Acoustic detection of impacts. & $\begin{array}{l}\text { Continuous monitoring. Localized } \\
\text { installation of sensors. Could be used in } \\
\text { conjunction with cathodic protection } \\
\text { detection. }\end{array}$ & $\begin{array}{l}\text { Detects rather than prevents damage. Sensors } \\
\text { attached to outside pipe wall. Only one chance to } \\
\text { detect transient signal. Issues of background noise } \\
\text { must be solved. May be too costly if close sensor } \\
\text { spacing is required. }\end{array}$ \\
\hline 7 & $\begin{array}{l}\text { Distributed optical fiber with } \\
\text { interferometr-ic detection. }\end{array}$ & $\begin{array}{l}\text { Continuous monitoring. Same form factor as } \\
\text { pipeline. Sensitive technique }\end{array}$ & $\begin{array}{l}\text { Continuous fiber must be installed along pipeline. } \\
\text { Methods are needed to distinguish hazardous and } \\
\text { benign encroachment. Detects changes to the entire } \\
\text { fiber cannot distinguish simultaneous events or } \\
\text { events plus benign encroachment. }\end{array}$ \\
\hline 8 & $\begin{array}{l}\text { Distributed optical fiber with optical time } \\
\text { domain reflectometry. }\end{array}$ & $\begin{array}{l}\text { Potential to monitor miles of pipeline from } \\
\text { each location.Continuous monitoring. Same } \\
\text { form factor as pipeline. Can detect and } \\
\text { distinguish simultaneous events at different } \\
\text { points along optical fiber. }\end{array}$ & $\begin{array}{l}\text { Continuous fiber must be installed along pipeline. } \\
\text { Methods are needed to distinguish hazardous and } \\
\text { benign encroachment. }\end{array}$ \\
\hline
\end{tabular}

*Part-sourced from [11].

Figure 2 is a map of major oil and gas pipelines in the Niger Delta. The sum of oil and gas pipelines in the Western and Eastern regions is indeed a congested field.

So far, it appears that the best proposal could be a combination of Impressed Alternating Cycle Current (IACC) and the Acoustic methods. The IACC would be employed in the short and congested relatively smaller diameter lines. The acoustic would be used for longer transmission, trunk and distribution lines. Further improvement in terms of cost and effectiveness however, is required for the acoustic system.

Directional drilling HDD pipe laying equipment was recently used to lay a gas pipeline 45 metres beneath the 1.7 km Escravos River [19]. This approach has been felt in different quarters to be the future oil and gas pipeline installation to end the pipeline vandalism and illegal oil bunkering in the oil industry in the Niger Delta region [20].

The technology seems attractive for new pipelines, especially long distance pipelines, but the attendant pipeline maintenance issues and over-burden problems remain a concern, especially in the future.

\section{Conclusions}

This section has, in summary term, attempted to discuss the complex and diverse subject of leaks and potential leak detection. The oil theft and pollution in the Niger Delta region have shown an increasing trend over the years and the consequence of technology and research not growing to cover the challenges posed by these could further complicate the social, economic and environmental concerns in this region.

There is indeed a growing need for potential leak detection technologies in the area of intended and unintended pipeline damages in the Nigeria Niger Delta as in many other part of the world. In proposing a combination of IACC and an acoustic system in this region, it is hoped that efforts would be made to test the integration 


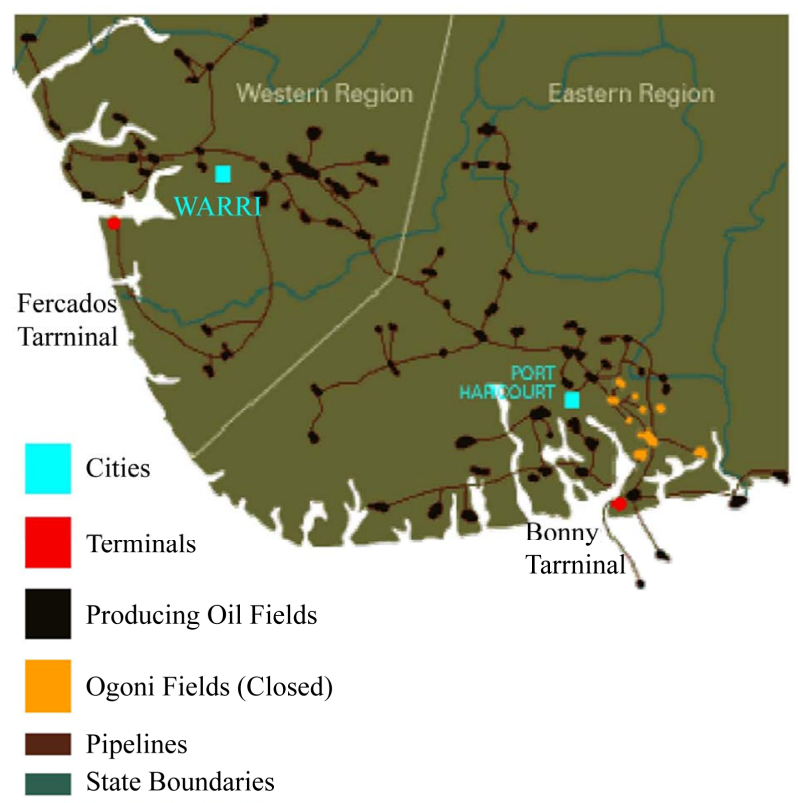

Figure 2. A Map of Nigerian Niger Delta showing some oil fields and pipelines (Source: Urhobo Historical Society, http://www.waado.org/nigerdelta/Maps/Oilfields.html, Assessed 26.07.2011).

and workability in terms of cost and effectiveness.

\section{Acknowledgements}

One does express his gratitude to AS Norske SHELL for provision of fund for the research studies in the area of oil/gas leak detection technologies. I also acknowledge the efforts of the Prof. Gudmestad O. T., for taken time to review and suggest improvement to this review work.

\section{REFERENCES}

[1] E. W. McAllister, "Pipeline Rules of Thumb Handbook: Quick and Accurate Solutions to Your Everyday Pipeline Problems," 6th Edition, 2005, pp. 547-556.

[2] L. P. E. Yo-Essien, "Oil Spill Management in Nigeria: Challenges of Pipeline Vandalism in the Niger Delta Region of Nigeria," National Oil Spill Detection and Response Agency (NOSDRA) Abuja, 2008. http://ipec.utulsa.edu/Conf2008/Manuscripts\%20\&\%20pr esentations\%20received/Eyo_Essien_2.pdf

[3] E. Ugwuani, "Shell Records 2580 Barrel Oil Spill," The Nations, 7 June 2011.

http://www.thenationonlineng.net/2011/index.php/busine ss/energy/8578-shell-records-2-580-barrels-oil-spill.html

[4] M. Sunmonu, "SPDC Response on Amnesty International Publication on Spills in the Niger Delta," 2010. http://www.shell.com/home/content/environment_society /society/nigeria/spills/

[5] K. N. Aroh, I. U. Ubong, C. L. Eze, I. M. Harry, J. C. Umo-Otong and A. E. Gobo, "Oil Spill Incidents and Pipeline Vandalization in Nigeria: Impact on Public
Health and Negation to Attainment of Millennium Development Goal: The Ishiagu Example,” Disaster Prevention and Management, Vol. 19, No. 1, 2010, pp. 70-87. Emerald Group Publishing Limited.

http://www.emeraldinsight.com/journals.htm?issn=0965$3562 \&$ volume $=19 \&$ issue $=1$

[6] P. O. Olajide, S. O. Ajisebutu, S. B. Williams and L. B. Ogbeifun, "Fish Kills and Physiochemical Qualities of Crude Oil Polluted River in Nigeria," Research Journal of Fisheries and Hydrobiology, Vol. 4, No. 3, 2009, pp. 55-64.

http://wenku.baidu.com/view/edd2ed7001f69e31433294d 3.html

[7] Amnesty International, "Nigeria: Petroleum, Pollution and Poverty in the Niger Delta,” Index: AFR 44/017/2009, 2009.

http://www.amnesty.org/en/library/asset/AFR44/017/200 9/en/e2415061-da5c-44f8-a73c-a7a4766ee21d/afr440172 009en.pdf

[8] S. Chastian, "Pipeline Right of Way Encroachment: Exploring Emerging Technologies That Address the Problem,” Documents and Resource for Small Business and Professionals, 2009.

http://www.docstoc.com/Docs/Document-Detail-Google. aspx?doc_id=64075370

[9] Press Release, "Magal Receives R\&D Contract to Enhance Its Pipeguard Technology for Protection of Gas Pipelines,” Research Sponsored by a Large US Gas Utility, 2011.

http://www.gsnmagazine.com/article/22740/magal_receiv es_r_d_contract_enhance_its_pipeguard_

[10] J. E. Heubler, "State-of-the-Art in Detection of Unauthorized Construction Equipment in Pipeline Right-of-Way," Transport Research Board of Academics, GTI Project 61139, 2002, p. 28.

[11] Free Patents Online, “All Inventions of Mankind”, Available at:

http://www.google.no/imgres?imgurl=http://www.freepat esonline.com/7203322-0-large.jpg\&imgrefurl=http://ww w.freepatensonline.com/7203322.html\&h=1330\&w=173 $1 \& \mathrm{sz}=206 \&$ tbnid $=$ NvvYHFhsysJ9SM:\&tbnh=115\&tbnw $=150 \&$ prev=/search\%3Fq\%3Dacoustic\%2Bdetector\%26t bm\%3Disch\%26tbo\%3Du\&zoom=1\&q=acoustic+detecto r\&hl=no\&usg=_1tcAnpIJqCMAWZIPYg-q5QlFrco=\&s $\mathrm{a}=X \&$ ei=tyMbTuyGF43Jsgb1oN3EDw\&ved=0CEYQ9Q EwBg

[12] The Website for the Offshore Oil and Gas Industry, "Pipeline Inspection and Maintenance," 2011.

http://www.offshore-technology.com/contractors/pipeline _inspec/

[13] J. Agbakwuru, “A Review of Pipeline Leaks and Inspection Technologies in the Oil and Gas Industry," Pipeline Course of the University of Stavanger, Unpublished, 2011.

[14] J. A. Agbakwuru, O. T. Gudmestad, J. Groenli and H. Skjaveland, "Development of Method/Apparatus for Close-Visual Inspection of under-Water Structures (Especially Pipelines) in Muddy and Unclear Water Condi- 
tion," Proceedings of the 30th International Conference on Ocean, Offshore and Arctic Engineering, OMAE, Rotterdam, 19-24 June 2011.

[15] GE Oil and Gas, "PII Pipeline Solution ThreatScan: Real Time Monitoring for Threats and Impacts on Pipelines”, 2010.

http://site.ge-energy.com/businesses/ge_oilandgas/en/pro d_serv/serv/pipeline/en/downloads/threatScan_us.pdf.

[16] US Department of Energy, Office of Fossil Energy, "Detection of Unauthorized Construction Equipment in Pipeline Right-of-Way, 2011.

http://www.fossil.energy.gov/fred/factsheet.jsp?doc=256 4\&projtitle=Detection\%20of\%20Unauthorized\%20Const ruction\%20Equipment\%20in\%20Pipeline\%20Right-ofWays

[17] G. L. Burkhardt and A. E. Crouch, "Realtime Monitoring of Pipelines from Third-Party Contact," Semi-Annual Technical Progress Report No.4, Cooperative Agreement
DE-FC26-03NT41878, Southwest Research Institute ${ }^{\circledR}$ Project 14.10211, 2005.

http://www.osti.gov/bridge/servlets/purl/859333-KJOMJ B/859333.pdf

[18] J. M. Muggleton and M. J. Brennan, "Leak Noise Propagation and Attenuation in Submerged Plastic Water Pipes,” Journal of Sound and Vibration, Vol. 278, No. 3, 2004, pp. 527-537. doi:10.1016/j.jsv.2003.10.052

[19] D. K. Olofin, Gulf Oil Co., Western Geophysical Co. and R. A. Will, "Acquisition and Processing of Shallow Water 3-D Seismic Surveys over Producing Fields in the Northwest Niger Delta Offshore,” Technology Conference, Houston, 6-7 November 1989.

[20] S. Adebayo, "HDD Technology Takes Pipeline Across 1.7 km Escravos River,” Fortune Business, 2010. http://www.nigerianbestforum.com/generaltopics/?p=606 28 